\title{
Insulin Resistance in firstborn offspring of mother who developed diabetes later in fourth decade: Are both related to possible maternal malnutrition?
}

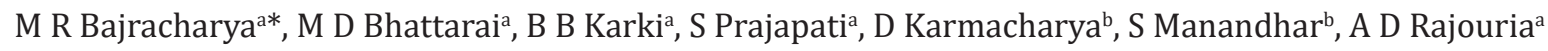 \\ ${ }^{a}$ National Academy of Medical Sciences (NAMS), Bir Hospital, Kathmandu, Nepal \\ ${ }^{b}$ Centre for Molecular Dynamics Nepal
}

DOI Name

http://dx.doi.org/10.3126/jaim.v3i2.14065

\section{Keywords}

Diabetes, HOMA, Insulin resistance, offspring,

Nepal

\section{Citation}

Bajracharya MR, Bhattarai MD, Karki BB, Prajapati

$S$, Karmacharya D, Manandhar S, Rajouria $A D$.

Insulin Resistance in firstborn offspring of mother

who developed diabetes later in fourth decade:

Are both related to possible maternal

malnutrition? Journal of Advances in Internal

Medicine 2014;03(02):56-61.

\section{ABSTRACT}

Back grounds and Aims: Diabetes mellitus is increasing each day. We aimed to study the insulin resistance (IR) in the offspring of people with diabetes and its relation with lifestyle and clinical factors.

Methods: This is a cross sectional study of IR in offspring over the age of 18 years and having parents with diabetes. Participants already diagnosed as having diabetes, suffering from any illness or using drugs that may have altered blood sugar levels were excluded. A fasting blood sample was taken for blood glucose and serum insulin level and IR was calculated using homeostatic model assessment for IR (HOMA -IR).

Results: Forty nine participants volunteered for the study of which $24.5 \%$ were found to have IR, the cut off value of HOMA -IR being 2.48. As compared to the later born offspring, the firstborn were six times more at risk for IR (Odds ratio 6.25, P value 0.015) and after adjustment for BMI, it was seven times (Odds ratio 7.29 , P value 0.011 ). IR was more in offspring with maternal diabetes than with paternal one. The mean age of diagnosis of diabetes in mothers having firstborn offspring with IR was 38.5 years as compared to 48.2 years of those having firstborn offspring without IR.

Conclusion: Higher risk of IR seen in the firstborn offspring whose mother later developed diabetes at fourth decade indicate the probability of relation of both conditions with possible maternal malnutrition during the first pregnancy. Further larger studies are required focusing on these aspects.

\section{BACKGROUND}

The incidence and prevalence of Type 2 Diabetes Mellitus (T2DM) is increasing day by day in epidemic magnitude worldwide affecting millions of people. A field survey done in Nepal showed the prevalence of diabetes mellitus and impaired glycaemia to be around $14.6 \%$ and $9.1 \%$ respectively for people above the age of 20 years in the urban population. In this study, the urban prevalence of diabetes is six times more than that of rural population. ${ }^{1}$

Similarly, a clustered-sampled population-based study of the urban areas of Nepal was conducted between 2001 to 2002.
In that study the prevalence of diabetes (known and newly diagnosed), IGT and impaired fasting glycaemia (IFG) were $19.0 \%, 10.6 \%$ and $9.9 \%$, respectively in individuals aged $\geq 40$ years. $^{2}$

Finding a high insulin resistance( IR ) in an off spring of a parent or parents with diabetes mellitus may lead to early awareness

\footnotetext{
* Corresponding author

Dr M R Bajracharya

Bir Hospital, NAMS, Kathmandu, Nepal

Email:manilbajra@yahoo.com
} 
to a possibility of developing diabetes many years later and thus making timely preventional steps possible.

Data from USA suggests that children with a positive family history of T2DM are more at risk of developing insulin resistance .$^{3,4} \mathrm{~A}$ study done in India in normoglycemic offspring of T2DM patients using homeostatic model assessment for insulin resistance ( HOMA-IR ) also found that these off springs had higher BMI, plasma insulin levels as compared to controls. ${ }^{5}$ A study done by Upadhyaya et al to find the prevalence of diabetes in first degree relatives of people with diabetes in Western Nepal found that the prevalence was about $17.33 \%{ }^{6}$ As Nepal is also vulnerable to this epidemic non communicable disease, a study like this will help to forecast the magnitude of the disease burden for the future and will help in making strategies to prevent the increase in incidence of the disease as well. This study was conducted with such aim as data regarding this is very scarce in Nepal.

\section{METHODOLOGY}

This is cross-sectional observational study conducted in 2013. Off springs over the age of 18 years with parents having T2DM coming to Bir Hospital and surrounding local health service providing centers were invited to participate in the study. Written consent was obtained from all participants and the research was approved by Institutional Review Board of National Academy Medical Sciences, Kathmandu, Nepal. Participants already diagnosed as having diabetes, suffering from any illness or using any drugs (eg. steroids) that may alter blood sugar levels were excluded from the study.

The participants underwent an interview and a questionnaire was filled up with details of occupation, physical exercise, eating habits, relevant family history, order of birth etc - Each participant underwent physical examination with measurement of blood pressure (after resting for 5 minutes) , height, weight. All participants had undergone an overnight fast and blood samples were taken in fasting conditions the next morning. Cold chain and storage facilities for blood samples for laboratory analysis were maintained as per requirements.

Fasting plasma glucose (FPG) was measured using enzymatic glucose oxidase peroxidase method and insulin was measured using commercial ELISA kits.

Insulin resistance was calculated from FPG and serum insulin values using the formula for HOMA-IR. The HOMA is a method used to quantify insulin resistance and beta-cell function and the method was first described under the name HOMA by Matthews et al. in $1985 .^{7}$

HOMA is found to be a simple and reliable tool for epidemiological purposes of assessing insulin sensitivity ${ }^{8}$ and studies have demonstrated its usefulness in monitoring treatment efficacy in T2DM ${ }^{9}$ including those taking sulphonylureas or diet alone. ${ }^{10}$

In this study, we had divided the Body Mass Index (BMI) as Normal : $18.0-22.9 \mathrm{~kg} / \mathrm{m}^{2}$, Overweight: $23.0-24.9 \mathrm{~kg} / \mathrm{m}^{2}$, Obesity: $\geq 25 \mathrm{~kg} / \mathrm{m}^{2}$ which is recommended for this region. ${ }^{11,12}$ Participant's weight was taken to the nearest $100 \mathrm{gm}$, while wearing light clothing.

A FPG value of less than $5.6 \mathrm{mmol} / \mathrm{L}$ was considered as having normal fasting glucose tolerance. ${ }^{13}$

For insulin resistance cut off value, it has been found to be different in different study populations and most studies have used a cut off value of $75^{\text {th }}$ percentile above which is considered as abnormal. ${ }^{14}$ Similarly, in our study too, we have used a cut off value from the $75^{\text {th }}$ percentile of the insulin resistance values.

Data was analyzed using SPSS version 17.0 and independent t tests, using bivariate analysis with chi square test (exact test where applicable). A P value of $<0.05$ was considered as statistically significant.

\section{RESULTS}

A total of 55 participants volunteered to take part in the study out of which 49 participants fulfilled the inclusion criteria and were included in the study. There were 29 male participants and 20 female participants in the study. In this study of 49 participants when the cut off value of 2.48 ( $75^{\text {th }}$ percentile) was taken, 12 participants were found to have insulin resistance that is almost one fourth of the participants.

The measurement of fasting serum insulin was significantly greater in the IR group than in the Non-IR group. There were no significant difference between age, BMI, blood pressure and FPG among the two groups (Table 1) .

Table1. Baseline characteristics of participants with and without insulin resistance

\begin{tabular}{lccc}
\hline & $\begin{array}{c}\text { Non insulin re- } \\
\text { sistant ( } \mathrm{n}=38)\end{array}$ & $\begin{array}{c}\text { Insulin } \\
\text { Resistant } \\
(\mathrm{n}=12)\end{array}$ & P value \\
& Mean (SD) & Mean (SD) & \\
\hline Age (yrs) & $30.00(9.42)$ & $28.50(7.66)$ & 0.620 \\
BMI Kg/m ${ }^{2}$ & $24.40(4.05)$ & $26.94(3.84)$ & 0.062 \\
Systolic BP (mm/Hg) & $109.95(9.27)$ & $114.33(10.26)$ & 0.171 \\
Diastolic BP (mm/Hg) & $69.68(8.16)$ & $71.50(8.40)$ & 0.507 \\
Fasting plasma blood & $4.44(0.41)$ & $4.43(0.24)$ & 0.922 \\
glucose (mmol/L) & & & \\
Serum Insulin & $7.18(2.62)$ & $21.84(9.16)$ & $<0.001$ \\
level $(\mu \mathrm{U} / \mathrm{ml})$ & & & \\
\hline
\end{tabular}


Students had significantly lower BMI as compared to the non student group but such differences were not observed for FPG, serum insulin and insulin resistance (Table 2).

Table 2. Mean values of various parameters in different subgroups

\begin{tabular}{|c|c|c|c|c|}
\hline & $\begin{array}{c}\text { BMI } \\
\text { Mean(SD) }\end{array}$ & $\begin{array}{c}\text { FPG } \\
\text { Mean(SD) } \\
\mathrm{mmol} / \mathrm{L}\end{array}$ & $\begin{array}{c}\text { Insulin } \\
\text { Mean(SD) } \\
\mu \mathrm{U} / \mathrm{ml}\end{array}$ & $\begin{array}{c}\text { Insulin } \\
\text { Resistance } \\
\text { Mean(SD) }\end{array}$ \\
\hline First born & $26.01(5.00)$ & $4.43(0.36)$ & $13.84(10.64)$ & $2.72(2.04)$ \\
\hline Non First born & $24.29(3.20)$ & $4.44(0.40)$ & $8.46(4.34)$ & $1.66(0.85)$ \\
\hline$P$ value & 0.149 & 0.874 & 0.038 & 0.035 \\
\hline Maternal DM & $25.19(4.65)$ & $4.47(0.29)$ & $12.01(7.62)$ & $2.39(1.50)$ \\
\hline Paternal DM & $23.90(3.21)$ & $4.48(0.48)$ & $9.61(8.35)$ & $1.85(1.45)$ \\
\hline P value & 0.346 & 0.949 & 0.369 & 0.270 \\
\hline Single parent DM & $24.45(3.95)$ & $4.47(0.40)$ & $10.78(7.98)$ & $2.11(1.48)$ \\
\hline Double parent DM & $26.62(4.28)$ & $4.32(0.30)$ & $10.71(8.65)$ & $2.13(1.83)$ \\
\hline P value & 0.102 & 0.227 & 0.981 & 0.970 \\
\hline Male offspring & $24.66(3.76)$ & $4.47(0.41)$ & $11.05(8.96)$ & $2.16(1.66)$ \\
\hline Female offspring & $25.55(4.62)$ & $4.38(0.33)$ & $10.36(6.76)$ & $2.05(1.44)$ \\
\hline P value & 0.465 & 0.422 & 0.772 & 0.821 \\
\hline Smokers & $24.52(3.12)$ & $4.31(0.36)$ & $16.69(13.84)$ & $3.15(2.43)$ \\
\hline Non smokers & $24.97(4.22)$ & $4.45(0.38)$ & $9.69(6.64)$ & $1.92(1.34)$ \\
\hline$P$ value & 0.803 & 0.395 & 0.044 & 0.068 \\
\hline Exercise & $25.23(4.10)$ & $4.37(0.24)$ & $9.68(5.02)$ & $1.90(1.03)$ \\
\hline No Exercise & $24.96(4.17)$ & $4.36(0.38)$ & $11.12(8.86)$ & $2.19(1.70)$ \\
\hline$P$ value & 0.842 & 0.464 & 0.596 & 0.580 \\
\hline Age up to 35 & 23.94(3.37) & $4.46(0.38)$ & $11.17(8.76)$ & $2.19(1.68)$ \\
\hline Age more than 35 & $28.77(4.38)$ & $4.36(0.38)$ & $9.37(5.00)$ & $1.85(1.06)$ \\
\hline P value & 0.000 & 0.486 & 0.519 & 0.531 \\
\hline$\geq 3$ Meals out of home/wk & $24.24(3.60)$ & $4.45(0.42)$ & $11.30(9.07)$ & $2.21(1.72)$ \\
\hline$<3$ Meals out of home/wk & $26.38(4.58)$ & $4.40(0.31)$ & $9.84(6.07)$ & $1.95(1.24)$ \\
\hline P value & 0.079 & 0.662 & 0.546 & 0.567 \\
\hline Having motorized Vehicle & $25.37(3.42)$ & $4.57(0.41)$ & $13.33(9.85)$ & $2.64(1.85)$ \\
\hline No motorized vehicle & $24.64(4.83)$ & $4.28(0.27)$ & $7.87(3.88)$ & $1.53(0.82)$ \\
\hline$P$ value & 0.550 & 0.007 & 0.014 & 0.009 \\
\hline Student & $22.34(3.01)$ & $4.27(0.28)$ & $10.33(7.60)$ & $2.00(1.61)$ \\
\hline Non student & $26.10(4.03)$ & $4.50(0.39)$ & $10.94(8.34)$ & $2.16(1.55)$ \\
\hline$P$ value & 0.003 & 0.057 & 0.813 & 0.750 \\
\hline Sendentary Life $\geq 5$ hrs day & $25.31(4.55)$ & $4.41(0.24)$ & $13.73(7.46)$ & $2.70(1.48)$ \\
\hline Sendentary Life $<5$ hrs day & $24.91(3.99)$ & $4.45(0.42)$ & $9.58(8.09)$ & $1.88(1.54)$ \\
\hline$P$ value & 0.765 & 0.745 & 0.105 & 0.094 \\
\hline
\end{tabular}

In this study as we compared insulin resistance among offspring having mother vs father with T2DM , there is more insulin resistance in offspring with maternal diabetes however there is not much difference in insulin resistance between having single parent with T2DM and both parents with T2DM. As shown in Table 3, a comparative analysis was done between possible risk factors in insulin resistant and non insulin resistant groups and it was observed to have statistically significant risk factors in birth order ( $p$ value 0.010 ), sedentary life as denoted of having $\geq 5$ hours/day screen time ( $p$ value 0.024 ).

Table 3. Comparison between possible risk factors in insulin resistant and non insulin resistant groups

\begin{tabular}{|c|c|c|c|c|}
\hline & & $\begin{array}{c}\text { Insulin } \\
\text { resistance } \\
n=12(\%)\end{array}$ & $\begin{array}{l}\text { Noninsulin } \\
\text { resistance } \\
n=37(\%)\end{array}$ & P value \\
\hline \multirow{2}{*}{ History of parental DM } & Single parent & $9(24.3)$ & $28(75.7)$ & \multirow[t]{2}{*}{0.962} \\
\hline & Both parents & $3(25.0)$ & $9(75.0)$ & \\
\hline \multirow{3}{*}{ History of DM in parents } & father & $3(15.8)$ & $16(84.2)$ & \multirow[t]{3}{*}{0.442} \\
\hline & mother & $6(33.3)$ & $12(66.7)$ & \\
\hline & both & $3(25.0)$ & $9(75.0)$ & \\
\hline \multirow{2}{*}{$\begin{array}{l}\text { Having motorized } \\
\text { vechile for commuting }\end{array}$} & yes & $9(34.6)$ & $17(65.4)$ & \multirow[t]{2}{*}{0.080} \\
\hline & no & $3(13.0)$ & $20(87.0)$ & \\
\hline \multirow{2}{*}{ Doing physical exercise } & yes & $3(25.0)$ & $9(75.0)$ & \multirow[t]{2}{*}{0.962} \\
\hline & no & $9(24.3)$ & $28(75.7)$ & \\
\hline \multirow{2}{*}{ Occupation } & student & $3(21.4)$ & $11(78.6)$ & \multirow[t]{2}{*}{0.753} \\
\hline & nonstudent & $9(25.7)$ & $26(74.3)$ & \\
\hline \multirow{2}{*}{ Gender of offspring } & male & $8(27.6)$ & $21(72.4)$ & \multirow[t]{2}{*}{0.788} \\
\hline & female & $4(20)$ & $16(80)$ & \\
\hline \multirow{2}{*}{ Order of birth } & First born & $9(42.9)$ & $12(57.1)$ & \multirow[t]{2}{*}{0.010} \\
\hline & laterborn & $3(21.4)$ & $25(78.6)$ & \\
\hline \multirow{2}{*}{ Sendentary life style } & yes & $7(50.0)$ & $7(50.0)$ & \multirow[t]{2}{*}{0.024} \\
\hline & no & $5(14.3)$ & $30(85.7)$ & \\
\hline \multirow{2}{*}{$\begin{array}{l}\text { Having more than } 3 \text { away } \\
\text { from home meals }\end{array}$} & yes & $8(25.8)$ & $23(74.2)$ & \multirow[t]{2}{*}{1.000} \\
\hline & no & $4(22.2)$ & $14(77.8)$ & \\
\hline \multirow{3}{*}{ Smoking status } & Current smoker & $3(50.0)$ & $3(50.0)$ & \multirow[t]{3}{*}{0.051} \\
\hline & Non smoker & $8(19)$ & $34(81.0)$ & \\
\hline & Ex smoker & $1(100.0)$ & $0(0.0)$ & \\
\hline \multirow{3}{*}{$\mathrm{BMI}\left(\mathrm{Kg} / \mathrm{m}^{2}\right)$} & $<22.9$ & $1(6.3)$ & $15(93.8)$ & \multirow[t]{3}{*}{0.097} \\
\hline & $23-24.9$ & $3(25.0)$ & $9(75.0)$ & \\
\hline & $\geq 25$ & $8(38.1)$ & $13(61.9)$ & \\
\hline
\end{tabular}

The mean age of diagnosis of T2DM in mothers having firstborn off spring with IR (not including participants with both parents with T2DM) was 38.5 years. This was lower than the mean age of diagnosis of T2DM in mothers having firstborn off spring without IR (48.2 years). Non of the participating offsprings' mothers had diabetes at the time of birth of the offspring.

In Table 4, we can see that with increasing BMI, there is also an 
increase in fasting serum insulin levels and insulin resistance although statistically not significant however such trend was not observed for fasting blood glucose.

Table 4. Increase in insulin and insulin resistance with BMI

\begin{tabular}{|c|c|c|c|c|c|c|c|}
\hline & $\begin{array}{c}\text { BMI } \\
\text { normal }\end{array}$ & $n=16$ & $\begin{array}{c}\text { BMI } \\
\text { over- } \\
\text { weight }\end{array}$ & $n=12$ & $\begin{array}{l}\text { BMI } \\
\text { Obese }\end{array}$ & $n=21$ & \\
\hline & Mean & SD & Mean & SD & Mean & SD & $p$ value \\
\hline $\begin{array}{l}\text { FBS } \\
(\mathrm{mmol} / \mathrm{L})\end{array}$ & 4.22 & 0.22 & 4.63 & 0.29 & 4.48 & 0.45 & 0.010 \\
\hline $\begin{array}{l}\text { Insulin } \\
(\mu \mathrm{U} / \mathrm{mL})\end{array}$ & 8.99 & 8.94 & 10.00 & 8.45 & 12.56 & 7.10 & 0.390 \\
\hline $\begin{array}{l}\text { Insulin } \\
\text { resistance }\end{array}$ & 1.67 & 1.56 & 2.07 & 1.76 & 2.48 & 1.41 & 0.296 \\
\hline
\end{tabular}

Bivariate analysis with logistic regression was also done for insulin resistance and $\mathrm{BMI}$ and single or both parental history of DM. It showed that the first born child was six times at risk of becoming insulin resistant as compared to later born children (Odds ratio $6.25,95 \% \mathrm{Cl} 1.43-27.37, \mathrm{P}$ value 0.015 ) and the same risk factor hold true with adjustment for single or both parents with diabetes (Odds ratio $6.48,95 \% \mathrm{Cl} 1.45$ 28.99, $P$ value 0.014).

After adjustment for BMI, the odds ratio for developing insulin resistance in the first born child increased to seven times that of a later born child (Odds ratio 7.29 , 95\% Cl 1.59-33.46, P value 0.011).

\section{DISCUSSION}

The most notable finding in our study is that as compared to the later born offspring, the firstborn were six times more at risk for IR which was seven times after adjustment for BMI. IR was more associated in offspring with maternal diabetes and the mean age of diagnosis of diabetes in mothers having firstborn offspring with IR was 38.5 years as compared to 48.2 years of those having firstborn offspring without IR. As mentioned earlier none of the participating off springs' mothers had diabetes at the time of birth of the offspring. It indicates that the IR in the firstborn offspring was not related with maternal hyperglycemia during pregnancy. The mean age of onset of diabetes in mother is lower than that seen in industrialized countries. ${ }^{15}$ Maternal malnutrition is a known risk factor of development of glucose intolerance in offspring. ${ }^{16,17}$ After the birth of a child, the mothers are well fed and their nutritional status and body weight increases, ${ }^{18}$ which decreases the risk of fetal malnutrition in the later pregnancies. The malnourished mothers themselves are at increased risk of development of diabetes if they gain excessive weight later. ${ }^{17}$ The improved feeding may increase the BMI of the mother excessively increasing their risk of development of diabetes later in life.${ }^{18}$ On the basis of such prevalent social trends and observations it thus raises the possibility that whether the development of IR in the firstborn child and of early diabetes in the mother are both related to the maternal malnutrition from one generation to another. A review article by Sanchez-Muniz et al emphasized that proper nutrition since the onset of pregnancy is essential for fetal pancreatic growth and development required for optimum glucose homeostasis during fetal life as well as preventing or delaying the onset of T2DM in adulthood. ${ }^{19}$

The increased possibility of development of insulin resistance in offsprings of people with T2DM has been shown by several studies. ${ }^{20-21} \mathrm{~A}$ study done by Preethi BL et al in Bangalore had compared insulin resistance in normoglycemic young adults and it was estimated by using physiological mathematical models like HOMA-IR, etc. and their formulas derived from Oral Glucose Tolerance Test (OGTT).$^{20}$ The study showed that siblings of people with diabetes had higher insulin resistance values and lower insulin sensitivity values. Studies done by Osei $\mathrm{K}$ et al on first degree relatives of African American Type 2 Diabetes patients showed that the triad of decrease insulin secretion, insulin action, and glucose effectiveness antecede the development of diabetes in these individuals. ${ }^{21} \mathrm{~A}$ cut off value of $75^{\text {th }}$ percentile has been used for both IR and serum insulin values in epidemiological studies. ${ }^{22}$ The cut off value for IR in our study is 2.48 . The IR cut of values can vary among different ethnic groups, age groups and risk groups. For the research of Ascao and team ${ }^{23}$ it was 2.6 and for the study done by Hydrie's team, it was $1.82 .{ }^{22}$

A cross-sectional study was done in Lahore, Pakistan in male offspring of parents having T2DM. In that study, the IR values for single parent with diabetes and both parents with diabetes were 2.4 and 3.17 respectively whereas in our study it was with IR 2.11 and 2.13 ( $P$ value 0.970 ) respectively. ${ }^{24}$ In our study, there is more fasting insulin levels and IR in the first born offspring as compared to the later born offspring (IR 2.72 vs 1.67 , p value 0.035 ). This is similar to a research done by Ayyavoo A et al which showed comparatively reduced insulin sensitivity in the first born child despite being taller and slimmer. ${ }^{25}$

Active travel such as walking and bicycling to work has been associated with reduced cardiovascular risk in the Indian population. ${ }^{26}$ In our study too those having their own motorized vehicle for daily commuting were also compared with those who do not have such vehicles and the mean value IR was statistically significant with 2.64 vs 1.53 p value 0.009 respectively. In our study, we can see that there is gradual increase in insulin resistance from normal weight (1.67) to 
overweight (2.07) to obese (2.48) showing a proportional increase of insulin resistance with BMI. The results observed are statistically significant for firstborn child, sedentary life style, owning motorized vehicle for commuting reinforcing the theory that both family history, genetics and life style are contributing factors for the development of insulin resistance and future risk of T2DM.

Limitations of the study.

The sample size is relatively small. There is no comparision with euglycemic clamp. Participants did not undergo prandial blood sugar testing, HbA1C , or Oral Glucose Tolerance Test. Almost all participants had normal fasting blood glucose and normal blood pressure which helps to reduce the possibility of already having diabetes or impaired fasting glucose and the effect of hypertension on IR which strengthens the role of inheritance of other factors influencing IR. The research does not include healthy controls i.e., offspring of parents without diabetes, the addition of which could have made some contributors for IR more comparative. However the later born and non-IR firstborn offspring and their parents provided some comparative data. There is variance in IR according to age groups, ethnicity etc. and no well established cut off values of insulin resistance that may predict the likelihood of future diabetes development.

\section{CONCLUSION}

Higher risk of insulin resistance is seen in the firstborn offspring whose mother later developed diabetes at fourth decade indicates the possibility of relation of both conditions with maternal malnutrition during their first pregnancy. Further larger studies are required focusing on these aspects.

\section{REFERENCES}

1 Singh DL, Bhattarai MD. Prevalence of diabetes and profile of diabetic patients in Nepal. PGMed J Nep 2004; 5: 7-12

2 Shrestha UK, Singh DL, Bhattarai MD. The prevalence of hypertension and diabetes defined by fasting and 2-h plasma glucose criteria in urban Nepal. Diabetic Medicine 2006; 23: 1130-1135

3 Danadian K, Balasekaran G, Lewy V, et al. Insulin sensitivity in African-American children with and without family history of type 2 diabetes. Diabetes Care 1999 Aug;22(8):1325-9.

4 Arslanian SA, Bacha F, Saad R, et al. Family history of type 2 diabetes is associated with decreased insulin sensitivity and an impaired balance between insulin sensitivity and insulin secretion in white youth. Diabetes Care 2005 Jan;28(1):115-9.

5 Praveen EP, Sahoo J, Khurana ML, et al. Insulin sensitivity and beta cell function in normoglycemic offsprings of individuals with type 2 diabetes mellitus : impact of line of inheritance. J Clin Endocrinol Metab. Jan-Feb 2012;16 (1).

6 Upadhyaya TL, Dhakal RR , Paudel B ,et al. Prevalence of diabetes in first degree relatives and ex-armies in Western Region of Nepal. Journal of Gandaki Medical College-Nepal .Oct. Dec. 2009;2(4):10 model assessment: insulin resistance and beta-cell function from fasting plasma glucose and insulin concentrations in man. Diabetologia 1985;28:412-9

8 Bonora E, Targger G, Alberiche M, et al. Homeostasis model assessment closely mirrors the glucose clamp technique in the assessment of insulin sensitivity: studies in subjects with various degree of glucose tolerance and insulin sensitivity. Diabetes Care 2000 ; 23:57-63

9 Katsuki A, Sumida Y, Gabazza EC, et al. Homeostasis Model Assessment Is a Reliable Indicator of Insulin Resistance During Follow-up of Patients With Type 2 Diabetes. Diabetes Care 2001 Feb;24 ( 2) 362-365

10 Emoto $\mathrm{M}$, Nishizawa $\mathrm{Y}$, Maekawa $\mathrm{K}$,et al. Homeostasis model assessment as a clinical index of insulin resistance in type 2 diabetic patients treated with sulfonylureas. Diabetes Care. 1999 May;22(5):818-22

11 Misra A, P Chowbey P, BM Makkar BM, et al for Consensus Group. Consensus Statement for Diagnosis of Obesity, Abdominal Obesity and the Metabolic Syndrome for Asian Indians and Recommendations for Physical Activity, Medical and Surgical Management. JAPI 2009 Feb ;57: 163-170

12 WHO expert consultation .Appropriate body-mass index for Asian populations and its implications for policy and intervention strategies. Lancet 2004; 363: 157-63

13 American Diabetes Association. Standards of Medical Care in Diabetes 2013. Diabetes Care 2013 Jan;36( suppl 1): $11-66$ 
14 Purnamasari D, Soegondo S, Oemardi M, et al . Insulin resistance profile among siblings of type 2 diabetes mellitus (preliminary study).Acta Med Indones. 2010 Oct; 42(4): 204-8.

15 International Diabetes Federation. IDF Diabetes Atlas, $6^{\text {th }}$ Edition ; 2013

16 Hales CN, Barker DJ. Type 2 (non-insulin-dependent) diabetes mellitus: the thrifty phenotype hypothesis. Diabetologia 1992;35(7):595-601

17 Bhattarai MD. Three Patterns of Rising type 2 Diabetes Prevalence in the World: Need to Widen the Concept of Prevention in Individuals into Control in the Community. J Nep Med Assoc 2009; 48: 173.

18 Bhattarai MD, Singh DL. Excessive weight gain after pregnancy in urban areas: One important area to prevent diabetes. Nepal Med Coll J. 2005 Dec;7(2):87-9.

19 Sanchez-muniz FJ, Gesteiro E, Espárrago Rodilla M, et al. Maternal nutrition during pregnancy conditions the fetal pancreas development, hormonal status and diabetes mellitus and metabolic syndrome biomarkers at birth. Nutr Hosp. 2013 Mar-Apr;28(2):250-74.

20 Preethi BL, Jaisri G, Kumar KM, et al. Assessment of insulin resistance in normoglycemic young adults. Fiziol Cheloveka. 2011 Jan-Feb; 37(1):118-25

21 Osei K, Rhinesmith S, Gaillard T, et al. Impaired insulin sensitivity, insulin secretion, and glucose effectiveness predict futuredevelopment of impaired glucose tolerance and type 2 diabetes in pre diabetic AfricanAmericans: implications for primary diabetes prevention. Diabetes Care. 2004 Jun;27(6):1439-46

22 Hydrie MZF, Basit A, Asher Fawwad A, et al. Detecting Insulin Resistance in Pakistani Subjects by Fasting Blood Samples. The Open Diabetes Journa 2012; 5: 20-4

23 Ascao JF, Pardo S, Real JT, et al. Diagnosing insulin resistance by simple quantitative methods in subjects with normal glucose metabolism. Diabetes Care. 2003 Dec;26(12):3320-5.

24 Shahid A, Lone KP, Saeed S, et al . Male offspring of both diabetic parents have higher insulin resistance and serum leptin levels compared to those with one diabetic parent. Hormones (Athens). 2008 Oct-Dec;7(4):313-9.

25 Ayyavoo A, Savage T, Derraik JG, et al. First-born children have reduced insulin sensitivity and higher daytime blood pressure compared to later-born children.J Clin Endocrinol Metab. 2013 Mar;98(3):1248-53.

26 Millett C,Agrawal S, Sullivan R, et al for the Indian Migration Study group" Associations between Active Travel to Work and Overweight, Hypertension, and Diabetes in India: ACross-Sectional Study. PLOS Medicine 2013 Jun; 10 (6 ) 